\title{
Squamous cell carcinoma of the prostate: long-term survival after combined chemo-radiation
}

Fernando Munoz ${ }^{1}$, Pierfrancesco Franco*1, Patrizia Ciammella1, Mario Clerico ${ }^{2}$, Mauro Giudici ${ }^{3}$, Andrea Riccardo Filippi ${ }^{1}$ and Umberto Ricardi ${ }^{1}$

Address: ${ }^{1}$ Department of Medical and Surgical Sciences, Radiation Oncology Unit, University of Torino, Ospedale S. Giovanni Battista, Torino, Italy, ${ }^{2}$ Department of Oncology, Medical Oncology, ASL 12, Biella, Italy and ${ }^{3}$ Pathology Unit, ASL 12, Biella, Italy

Email: Fernando Munoz - fmunoz@iol.it; Pierfrancesco Franco* - pier4377@yahoo.it; Patrizia Ciammella - patriziaciammella@yahoo.it; Mario Clerico - mario.clerico@asl12.piemonte.it; Mauro Giudici - mauro.giudici@asl12.piemonte.it; Andrea Riccardo Filippi - andrea.filippi@unito.it; Umberto Ricardi - umberto.ricardi@unito.it

* Corresponding author

Published: 3 April 2007

Radiation Oncology 2007, 2:15 doi:10.1186/1748-717X-2-15
Received: 2 February 2007

Accepted: 3 April 2007

This article is available from: http://www.ro-journal.com/content/2/I/I5

(C) 2007 Munoz et al; licensee BioMed Central Ltd.

This is an Open Access article distributed under the terms of the Creative Commons Attribution License (http://creativecommons.org/licenses/by/2.0), which permits unrestricted use, distribution, and reproduction in any medium, provided the original work is properly cited.

\begin{abstract}
Background: Carcinoma of the prostate gland is the most frequent malignant tumour affecting male population. While the large majority of tumours is represented by adenocarcinoma, pure squamous cell carcinoma comprises only $0,5-1 \%$ of all prostate neoplastic lesions.

It is characterised by a high degree of malignancy, commonly metastasising to the bone (mainly with osteolytic lesions), liver and lungs with a median survival time of 14 months.

Several therapeutic approaches have been employed in the effort to treat prostate pure squamous cell carcinoma, including radical surgery, radiotherapy, chemotherapy and hormonal therapy. All of them mostly failed to gain a significant survival benefit.

Case report: We herein report on a case of pure squamous cell carcinoma of the prostate approached with combined-modality treatment, with the administration of 3 courses of cisplatin 75 $\mathrm{mg} / \mathrm{m}^{2}$ on day I and continous infusion 5 -fluorouracil $750 \mathrm{mg} / \mathrm{m}^{2}$ on day I to 5 and, subsequently, radiotherapy, with the delivery of a total dose of $46 \mathrm{~Gy}$ to the whole pelvis, with additional boost doses of 20 Gy to the prostatic bed and adjunctive $6 \mathrm{~Gy}$ to the prostate gland (72 Gy in total). The patient remained free of disease for 5 years, finally experiencing local relapse and, subsequently, dying of acute renal failure due to bilateral uretero-hydro-nephrosis.

In addition, we provide a complete overview of all reported cases available within the medical literature.

Conclusion: Since it remains questionable which should be the most appropriate therapeutic approach towards prostate pure squamous cell carcinoma, our report demonstrates that a prolonged disease control, with a consistent survival time, may be achieved by the combination of an effective local treatment such as radiotherapy with systemic infusion of chemotherapeutic drugs.
\end{abstract}




\section{Background}

Carcinoma of the prostate gland is the most frequent malignant tumour affecting male population [1]. The large majority of prostate tumours is represented by the adenocarcinoma histotype (up to 95\%), while small cell, squamous cell, transitional cell, signet ring cell, mucinous and mixed types carcinomas occurs in less than $2 \%$ of cases [2,3]. Pure squamous cell carcinoma (PSCC) comprises only $0,5-1 \%$ of all prostate carcinomas [4]. Therefore clinical manifestations, natural history, prognosis and treatment options can be found only in anecdotal descriptions. It usually occurs in the seventh decade of age, with symptoms of urinary obstruction (due to bladder outlet obstacle) or bone pain due to osseous metastases [5]. Deemed rather more malignant than adenocarcinoma, PSCC commonly metastasises to the bone (mainly with osteolytic lesions), liver and lungs with a median post-diagnosis survival time estimated to be 14 months [6]. From the diagnostic point, serum Prostate-specific antigen (PSA) and prostatic acid phosphatase (PAP) commonly show values within the normal range, even in a metastatic disease context. However, squamous cell carcinoma (SCC) antigen might be elevated, allowing a serologic monitoring of disease status [7]. While radical prostatectomy and radiation are the only potentially curative options for prostate adenocarcinomas, several therapeutic approaches have been employed in the management of PSCC of the prostate, such as radical surgery, radiotherapy, chemotherapy and hormonal therapy. All of them have not been able to obtain long-lasting objective responses, neither in terms of local control, nor in terms of systemic efficacy. We herein present a case of PSCC of the prostate treated with a combined chemoradiotherapeutic approach, resulting in a prolonged disease-free survival of 5 years. Moreover, we provide a systematic overview of all reported cases available within the medical literature.

\section{Case report}

In June 2001, a 76 years old male was referred to our institution hospital with clinical signs and symptoms of acute urinary retention, complaining of voiding difficulties during the previous 2 months. On catheterisation, $600 \mathrm{ml}$ of urine could be rescued. Physical examination was unremarkable, except from digital rectal examination which disclosed an uneven swollen and enlarged prostate gland, of stony-hard consistency, with an irregular capsule profile. The patient had been healthy until the time of our observation. No history of radiation and hormonal therapy could be highlighted. Hence, a complete diagnostic work-up was planned.

Serum PSA and PAP showed in-range values. Transrectal ultrasound demonstrated hypoechoic lesions in the left peripheral zone of the prostate gland. Excretion urogram, urine cytology and urethro-cystoscopy were negative for malignancy, while bladder neck was slightly elevated on cystoscopy.

An abdominal and pelvic computed tomography (CT) scan was then performed, disclosing an irregularly enlarged prostate with a peripheral hypodense mass within, compressing the base of the bladder and disrupting the prostatic anatomy. No enlarged lymphnodes could be detected at any abdominal site.

On magnetic resonance imaging (MRI), the boundary between the transition zone and the peripheral zone of the prostate gland was unclear and the signal intensity had decreased in the left peripheral zone on T2-weighted images. Extra-capsular disease could be documented in at least 2 sites of the prostatic profile. No osseous spread could be observed at total body bone scan.

Sextant transrectal ultrasound-guided needle biopsy of the prostate was subsequently performed, with histological examination demonstrating nests and sheets of moderately differentiated squamous carcinomatous cells characterised by intercellular bridges. Focal areas presented with evidence of keratin pearl formation. No squamous metaplasia or transitional cell or adenocarcinomatous components could be observed.

Immunohistochemically, the PSCC component was non reactive for PSA, PAP and cytokeratin 7 and 20, but stained positive for high molecular weight cytokeratin (Figure 1,2). Considering all the data mentioned above, a diagnosis of AJCC-UICC Stage III (cT3aNOM0) prostate PSCC was then made.

The patient was given 3 courses of chemotherapy (CT) with cisplatin (CDDP) $75 \mathrm{mg} / \mathrm{m}^{2}$ on day 1 and continous infusion 5 -fluorouracil (5-FU) $750 \mathrm{mg} / \mathrm{m}^{2}$ on day 1 to 5 .

He subsequently underwent a full-course of radiation therapy (RT) using linear accelerator (18 MV photons), with a conventional four-field box technique up to $46 \mathrm{~Gy}$ to the whole pelvis followed by a boost dose to the prostate bed of 20 Gy and by an adjunctive dose of 6 Gy to the prostate gland ( $72 \mathrm{~Gy}$ in total). The patient was treated in supine position, with a six-field conformal field arrangement, delivered using three-dimensional conformal RT. Treatment was, generally, well tolerated, with no acute toxicity recorded.

After therapy had been completed, the patient was periodically examinated, with a clinical, radiological and serologic follow-up. He remained free from disease for 5 years, finally relapsing locally within the pelvis and subse- 


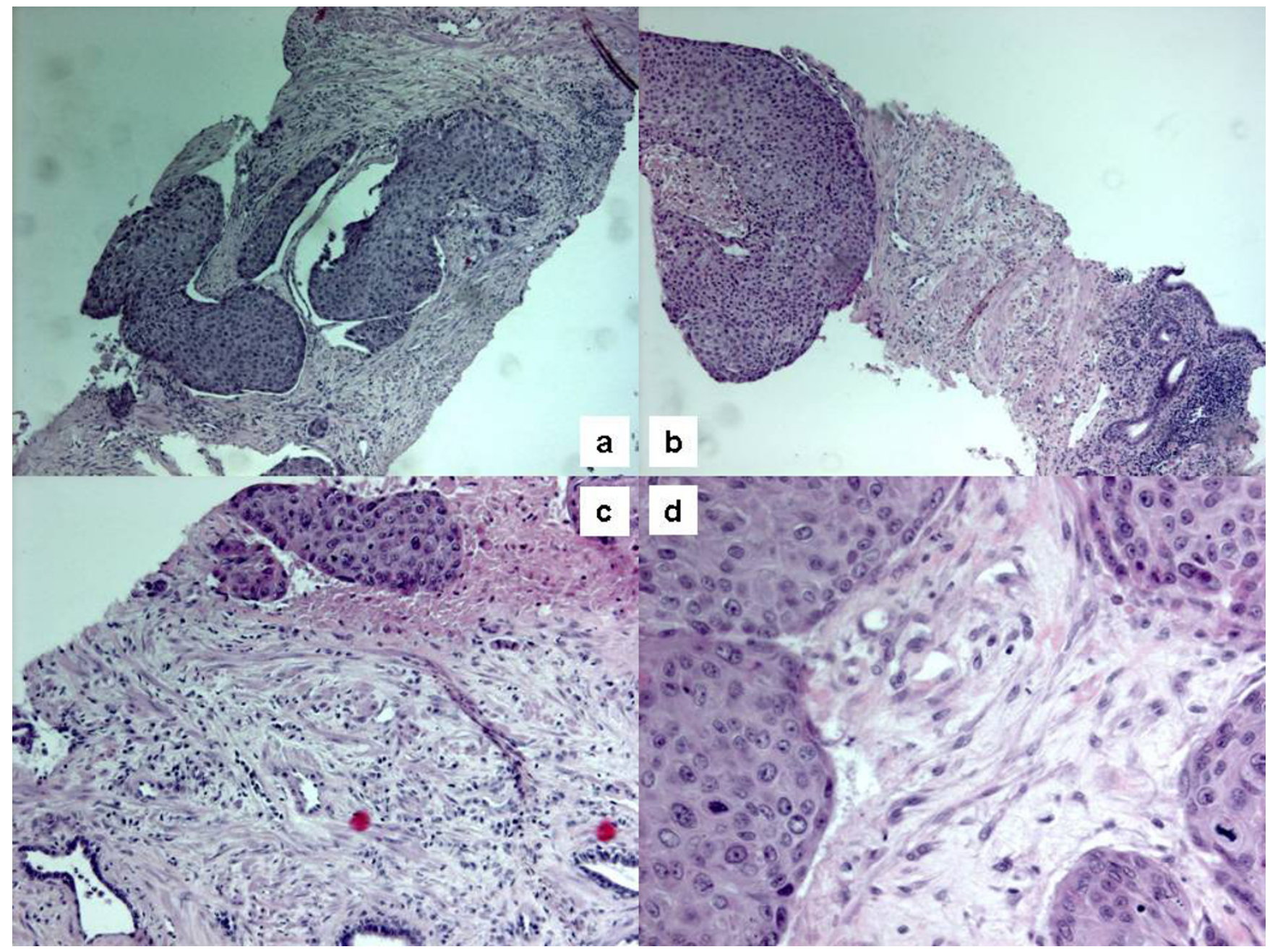

\section{Figure I}

Hematoxilin and eosin-stained sections showing solid sheets of squamous cells infiltrating the right lobe of the prostate (a; original magnification I0x) and the left lobe (b, c; original magnification I0x and 20x, respectively). Mytotic activity may also be observed (d; original magnification $40 x$ ).

quently dying of acute renal failure due to bilateral uretero-hydro-nephrosis in June 2006.

\section{Discussion}

PSCC of the prostate gland is an extremely rare pathological and clinical entity. Its histogenesis remains unclear. Mainly 2 principal origins are presumed for the neoplastic cells: the basal or reserve cells of prostatic acini, as pointed out by Sieracki, and the transitional epithelium lining the urethra or major ducts, as preferred by Kahler and Thompson et al [8-10]. Several theories have been proposed in order to explain prostate PSCC histogenesis: 1) a metaplastic transformation of adenocarcinoma cells, 2) a collision-type tumour, with the squamous component developing from metaplastic foci after radiation or hormonal therapy, 3) possible deviation from pluripotent stem cells capable of multidirectional differentiation [11-
14]. It has been speculated that the squamous cell component might be derived from squamous metaplasia of acini and ductal elements following radiation or hormonal therapy for prostatic adenocarcinoma [13]. While squamous metaplasia is known for occurring within the prostate gland during chronic prostatitis, around prostatic infarcts and after estrogen therapy or radiation therapy, malignant transformation is rare [8]. Moreover, even though prostate PSCC has been described in association with the use of a luteinising hormone-releasing hormone agonist and flutamide or after seed implantation for adenocarcinoma, all of these explanations could not reach satisfactory evidence $[15,16]$.

Mott suggested strict criteria for the diagnosis of primary PSCC: (i) a clearly malignant neoplasm as judged by invasion, disordered growth and cellular anaplasia; (ii) defi- 


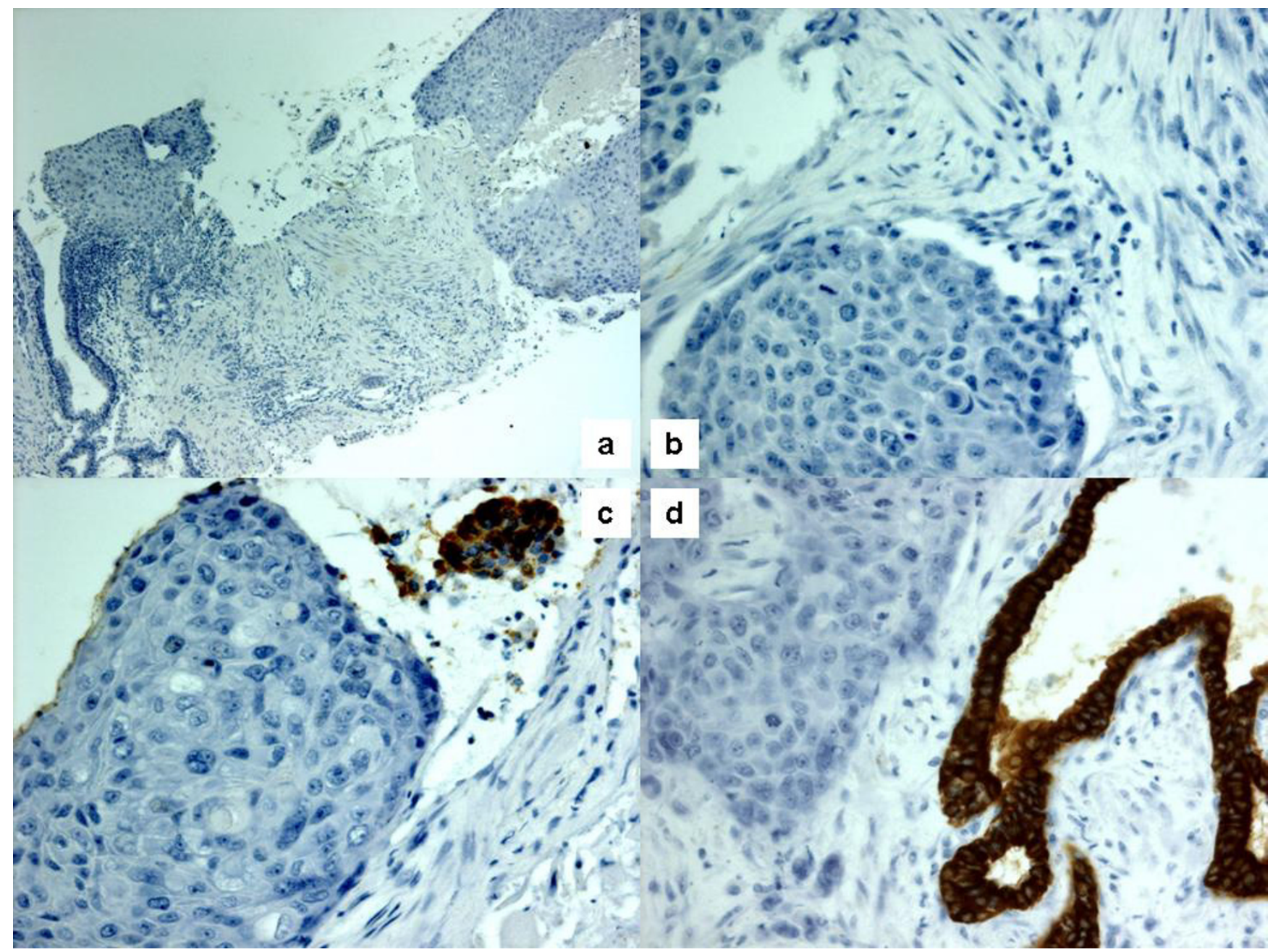

\section{Figure 2}

Immunohistochemistry showed negativity to cytokeratin 7 (a; original magnification I0x) and cytokeratin 20 (b; original magnification 40x). Squamous carcinoma cells also stained negative for PSA and PAP, while adjacent remaining glands stained positive (c, d; original magnification $40 x$ ).

nite squamous features of keratinization, squamous pearls and/or numerous distinct intercellular bridges; (iii) a lack of any glandular or acinar pattern (such a finding should be interpreted as evidence of adenocarcinoma with squamous metaplasia); (iv) no prior estrogen therapy; (v) an absence of primary squamous cancer elsewhere, particularly within the bladder [4].

A dismal prognosis has been usually associated with PSCC of the prostate (see Table 1 for details). The average survival time has been estimated to be 14 months [6]. As reported by Thompson et al, 5 out of 7 patients of their series survived less than 1 year [10]. In this context, scant information is available hitherto concerning the most valid treatment option for prostate PSCC. It does appear feasible that at least some localised tumours can be resected with similar modalities to comparably staged adenocarcinoma of the prostate and long-term survivors in this setting have been reported [10,17-19]. Little et al treated 2 patients with an aggressive surgical approach, consisting of radical cysto-prostatectomy and bilateral pelvic lymphadenectomy with an additional total urethrectomy in order to assure negative distal urethral margins: one patient remained free from disease 40 months after initial diagnosis, while the other died of lung metastases 25 months after diagnosis [17]. Gray et al performed transpubic radical cysto-prostatectomy with complete urethrectomy and bilateral pelvic node dissection in one patient. Moreover the pubic symphysis was excised and an abdominoperineal resection of the rectum was accom- 
plished with a sigmoid colostomy. Unfortunately, that patient died 6 months after surgery of perineal recurrence [18].

In Japan the longest survivor, who has been described, had a tiny suburethral PSCC; he remained free of recurrence for 6 years, after local excision, as reported by Masuda et al [19]. As far as tumour response to therapy is concerned, prostate PSCC is generally refractory to hormonal manipulation, while few cases might be susceptible to CT and RT. Several drugs have been employed, mainly basing on the experience with epithelial tumours located in other anatomical sites. CDDP-based regimens are the most established ones, possibly combined with bleomycin (BLM), peplomycin (PEP) and methotrexate (MTX). CT may be used as a single agent in a metastatic disease setting or in a combined modality approach, expecially in locally advanced disease. In this context, Uchibayashi $e t$ al achieved a favourable local tumour control for 21 months after trans-urethral prostatectomy by means of local irradiation and, subsequently, intravenous administration of BLM and intra-arterial administration of CDDP [20]. Okada et al achieved a 18 months disease-free survival with $50 \mathrm{~Gy}$ of pelvic RT plus an additional boost of 10 Gy and systemic administration of PEP and CDDP [21].

Imamura et al used CT within an adjuvant setting, after radical cystoprostatectomy with positive surgical margins. The patient received the MPD regimen with CDDP, PEP and MTX. No evidence of recurrence could be detected 5 years after treatment [22].

Corder et al treated one patient with pulmonary metastases from prostate PSCC with the administration of adriamycin $20 \mathrm{mg} / \mathrm{m} 2$ daily for 3 days, in 21-days cycles, achieving marked regression of pulmonary nodes. Tumour response lasted 5 months [23]. One patient receiving RT survived almost 9 years as reported by Sieracki et al [8].

In conclusion, from this concise overview of all reported cases, it appears evident that no definitive conclusions can be drawn up to now regarding the best available treatment option towards prostate PSCC. Nonetheless, certain features might be noteworthy. In a clinical situation of an organ-confined disease, radical surgical extirpation should be performed. The extent of the surgical procedure remains unclear. Radiation therapy as a single modality treatment in limited-stage disease seems to be an investigational approach. Moreover, the role of RT within an adjuvant setting after surgery has rarely been explored. However, within a context of a locally-advanced disease, RT might be usefull (with doses of at least 66 Gy, deriving data from SCC at other anatomic sites), expecially if com- bined with chemotherapy, in order to achieve local control with organ functional preservation. The possibility to diminish the probability of systemic spread may also be hypotesised. The most effective drugs to be used have yet to be established. More data are needed in the future, maybe collected in a retrospective multicentric setting or through rare cancer networks, in order to, supposedly, enlighten this subject.

\section{Financial competing interests}

The author(s) declare that they have no competing interests.

\section{Authors' contributions}

FM treated the patient and contributed in the critical revision. PF drafted the manuscript. PC contributed in the acquisition, analysis and interpretation of data. MC treated the patient and contributed in the acquisition, analysis and interpretation of data. MG supplied the pathological specimens. ARF contributed in the critical revision. UR gave final revision and approval. All authors read and approved the final manuscript.

\section{Acknowledgements}

Written consent was obtained from patient's relatives for publication of this report.

\section{References}

I. Bracarda S, de Cobelli O, Greco C, Prayer-Galetti T, Valdagni R, Gatta G, de Braud F, Bartsch G: Cancer of the prostate. Crit Rev Oncol/Hematol 2005, 56:379-396.

2. Petersen R: Urologic Pathology 2nd edition. Philadelphia: JB Lippincott; 1986.

3. Randolph TL, Amin MB, Ro JY, Ayala AG: Histologic variants of adenocarcinoma and other carcinomas of prostate: pathologic criteria and clinical significance. Mod Pathol 1997, 10:612-619.

4. Mott LJ: Squamous cell carcinoma of the prostate. Report of 2 cases and review of the literature. J Urol 1979, I 2 1:833-835.

5. Mohan H, Bal A, Punia RP, Bawa AS: Squamous cell carcinoma of the prostate. Int J Urol 2003, I0: I I4-I I6.

6. Moskovitz B, Munichor M, Bolkier M, Livne PM: Squamous cell carcinoma of the prostate. Urol Int 1993, 51:181-I83.

7. Okamoto T, Ogiu K, Sato M, Kaneko T, Suzuki Y, Tanji S, Fujioka T: Primary squamous cell carcinoma of the prostate: a case report. Hinyokika Kiyo 1996, 42:67-70.

8. Sieracki JC: Epidermoid carcinoma of the human prostate: report of three cases. Laboratory Invest 1955, 4:232-240.

9. Kahler JE: Carcinoma of the prostate gland: a pathologic study. J Urol 1939, 41:557-574.

10. Thompson GJ, Albers DD, Broders AC: Unusual carcinomas involving the prostate gland. J Urol 1953, 69:416-425.

II. Bennet RS, Edgerton EO: Mixed prostatic carcinoma. J Urol I973, I 1 0:56|-563.

12. Devaney DM, Dorman A, Leader M: Adenosquamous carcinoma of the prostate: a case report. Hum Pathol 1991, 22:1046-1050.

13. Moyana TN: Adenosquamous carcinoma of the prostate. Am J Surg Pathol 1987, I I:403-407.

14. Paolo G, Henry JC, Antino C, Melanie JC: Adenosquamous carcinoma of the prostate. Hum Pathol 1995, 26: I23-I 26.

15. Braslis KG, Davi RC, Nelson E, Civantos F, Soloway MS: Primary squamous cell carcinoma of the prostate: a transformation from adenocarcinoma after the use of a luteinizing hormone-releasing hormone agonist and flutamide. Urology 1995 , 45:329-331. 
Table I: Overview on clinical reports

\begin{tabular}{|c|c|c|c|}
\hline Authors & $\mathbf{N}^{\circ}$ of cases & Treatment Options & Outcome \\
\hline \multicolumn{4}{|l|}{ I. Radical surgery reports } \\
\hline Baker et al and Arnheim $[25,26]$ & 4 & Orchiectomy/TURP/RP & Survival times: I to $3 \mathrm{mo}$ \\
\hline \multirow[t]{2}{*}{ Thompson et al $[10]$} & 7 & TURP/Orchiectomy/ES & Survival times: 3 mo. -6 yrs range \\
\hline & & & $5 / 7$ pts survived less than I year \\
\hline Sieracki [8] & 3 & RP/RT/ES & Survival times: 8 days- 9 yrs range \\
\hline Gray et al [18] & 1 & RP/Miles & Died I year after diagnosis \\
\hline Corder et al [23] & 1 & TURP/RP/RT/Adriamycin & 5 mo. response to $\mathrm{CT}$ \\
\hline Samsonov [3I] & 3 & $\mathrm{RP}$ & NA \\
\hline Al Adnani [32] & 2 & RP & Not reported \\
\hline Asuero et al [33] & 1 & $\mathrm{RP}$ & Alive I year after treatment \\
\hline Sarma et al [35] & 1 & RCP/TP/SC/PS/Miles & Died 6 mo. after diagnosis of d-MTS \\
\hline Masuda et al [19] & 1 & $\mathrm{RP}$ & Disease-free 6 yrs after surgery \\
\hline Moskovitz et al [6] & 1 & RP & Died 5 mo. after diagnosis \\
\hline \multirow[t]{2}{*}{ Little et al [17] } & 2 & RCP/PLND/TURP & Disease-free 40 mo. after surgery \\
\hline & & RCP/PLND & Lung MTS 25 mo. after diagnosis \\
\hline Braslis et al [15] & 1 & $\mathrm{RCP}$ & Disease-free 6 mo. after surgery \\
\hline Okamoto et al [7] & 1 & RP/PLND/MPD & Died 14 mo. after surgery \\
\hline Imamura et al [22] & 1 & $\mathrm{RCP} / \mathrm{MPD}$ & Disease-free 5 yrs after surgery \\
\hline Kanthan et al [45] & 6 & $\mathrm{RP} / \mathrm{RT} / \mathrm{CT}$ & Survival rates from I to $13 \mathrm{mo}$. \\
\hline
\end{tabular}

2. Radio-chemotherapy combined modality treatment reports

\begin{tabular}{llll}
\hline Inaba et al [49] & $\mathrm{I}$ & TURP/CDDP/RT & Died I3 months after diagnosis \\
Kuwahara et al [36] & $\mathrm{I}$ & TURP/CDDP/PEP/RT & Died 9 mo. after diagnosis \\
Uchibayashi et al [20] & $\mathrm{I}$ & TURP/Local RT/CDDP/BLM & Disease-free 21 mo. after diagnosis \\
Okada et al [21] & $\mathrm{I}$ & Local RT/CDDP/PEP & Disease-free I8 mo. after diagnosis \\
Present case & $\mathrm{I}$ & RT/CDDP/5-FU & 5 yrs disease-free survival
\end{tabular}

\section{Miscellaneous}

\begin{tabular}{|c|c|c|c|}
\hline Ray et al [27] & I & RT & Not reported \\
\hline Kastendieck et al [28] & 1 & TURP/Orchiectomy/ES & Died 2 months after diagnosis \\
\hline \multirow[t]{2}{*}{ Mott [4] } & 2 & TURP/RT & Died 8 mo. after diagnosis \\
\hline & & Orchiectomy/RT/DES & Died 5 months after diagnosis \\
\hline Sharma et al [29] & 1 & Orchiectomy & Died during diagnostic procedures \\
\hline Miller et al [16] & 1 & CDDP/5-FU/Tax & SD for 6 months \\
\hline Perez Garcia et al [37] & 1 & RT & Alive 5 mo. after treatment \\
\hline Nabi et al $[4 I]$ & 2 & TURP/Adriamycin & Died 5 mo. after diagnosis \\
\hline Goto et al [42] & 1 & MTX/Pirarubicin/CDDP/TPE & Disease-free $12 \mathrm{mo}$. after therapy \\
\hline Mayayo et al [44] & I & Local RT & Died 7 mo. after diagnosis \\
\hline John et al [47] & I & TURP/RT & Died 24 mo. after diagnosis \\
\hline Di Pietro et al [48] & I & TURP & Died during diagnostic work-up \\
\hline
\end{tabular}

\section{Anecdotal reports}

\begin{tabular}{llll}
\hline Spagnol [24] & I & None & Died 2 days after diagnosis \\
Kahaler [9] & 6 & Not reported & Not reported \\
Okamura et al [30] & 1 & NA & NA \\
Wernert et al [34] & 1 & Not reported & Not reported \\
Ulloa et al [38] & 1 & Not reported & NA \\
Rahmanou et al [39] & 1 & None & Not reported \\
Puyol et al [40] & $\mathrm{I}$ & None & Local PD 6 mo. after diagnosis \\
Herrera et al [43] & $\mathrm{I}$ & None & Died 2 mo. after diagnosis \\
Mohan et al [5] & $\mathrm{I}$ & Not reported & Discontinued follow-up \\
Parwani et al [46] & 8 & Survival times: 5-48 mo.
\end{tabular}

Only pure squamous cell carcinoma of the prostate gland have been included. TURP: transurethral resection of prostate; RP: radical prostatectomy; RT: radiotherapy; CT: chemotherapy; NA: not available (mainly due to articles written in languages others than English); ES: estrogen; DES: diethylstilbesterol; mo.: months; yrs: years; RCP: radical cystoprostatectomy; TP: total penectomy; SC: scrotectomy; PS: pubic symphysectomy; Miles: abdominoperineal resection of the rectum; d-MTS: distant metastases; CDDP: cisplatin; PEP: peplomycin; PLND: pelvic lymphadenectomy; 5FU: 5-fluorouracil; Tax: paclitaxel; MPD: methotrexate-peplomycin-cisplatin; BLM: bleomycin; MTX: methotrexate; TPE: total pelvic exenteration. 
16. Miller VA, Reuter V, Scher HI: Primary squamous cell carcinoma of the prostate after radiation seed implantation for adenocarcinoma. Urology 1995, 46: III-II3.

17. Little NA, Wiener JS, Walther PJ, Paulson DF, Anderson EE: Squamous cell carcinoma of the prostate: 2 cases of a rare malignancy and review of the literature. J Urol 1993, 149:137-139.

18. Gray GF Jr, Marshall VF: Squamous cell carcinoma of the prostate. J Urol 1975, I I 3:736-738.

19. Masuda H, Yamada T, Nagahama K, Nagamatu H, Negishi T: Primary squamous cell carcinoma of the prostate: A case report. Jpn J Urol Surg 1992, 5:519-521.

20. Uchibayashi T, Hisazumi H, Hasegawa M, Shiba N, Muraishi Y, Tanaka $\mathrm{T}$, Nonomura A: Squamous cell carcinoma of the prostate. Scand J Urol Nephrol 1997, 3 I:223-224.

21. Okada E, Kamizaki H: Primary squamous cell carcinoma of the prostate. Int J Urol 2000, 7:347-350.

22. Imamura $\mathrm{M}$, Nishiyama $\mathrm{H}$, Ohmori $\mathrm{K}$, Nishimura $\mathrm{K}$ : Squamous cell carcinoma of the prostate without evidence of recurrence 5 years after operation. Urol Int 2000, 65:122-124.

23. Corder MP, Cicmil GA: Effective treatment of metastatic squamous cell carcinoma of the prostate with adriamycin. J Urol 1976, I I 5:222.

24. Spagnol G: Epitelioma pavimentoso corneificante primitivo della prostata. Pathologica 1926, I 8:590-596.

25. Baker WJ, Carney JF: Squamous cell carcinoma of prostate. J Urol 1950, 64:752-757.

26. Arnheim FK: Carcinoma of the prostate. A study of the postmortem findings in 176 cases. J Urol 1948, 60:599-603.

27. Ray GR, Cassady JR, Bagshaw MA: Definitive radiative therapy of carcinoma of the prostate. A report on 15 years of experience. Radiology 1973, 106:407-418.

28. Kastendieck H, Altenahr $\mathrm{E}$ : The squamous cell carcinoma of the prostate as an example of metaplasia in a tumor. $Z$ Krebsforsch Klin Onkol Cancer Res Clin Oncol 1974, 82:335-340.

29. Sharma SK, Malik AK, Bapna BC: Squamous cell carcinoma of the prostate. Indian J Cancer 1980, I7: I 34- I35.

30. Okamura K, Ito K, Sahashi M, Shimoji T: Primary squamous cell carcinoma of the prostate: a case report. Nippon Hinyokika Gakkai Zasshi 1984, 75:979-983.

31. Samsonov VA: Prostatic squamous cell cancer and its differential diagnostic contrast with squamous cell metaplasia. Ark Patol 1984, 46:23-29.

32. Al Adnani MS: Schistosomiasis, metaplasia and squamous cell carcinoma of the prostate: histogenesis of the squamous cancer cells determined by localization of specific markers. Neoplasma 1985, 32:613-622.

33. Asuero MM, Gomez VM, Leal AJ: A case of epidermoid carcinoma of the prostate. Arch Esp Urol 1987, 40:68I-684.

34. Wernert N, Goebbels R, Bonkhoff H, Dhom G: Squamous cell carcinoma of the prostate. Histopathology 1990, 17:339-344.

35. Sarma DP, Weilbaecher TG, Moon TD: Squamous cell carcinoma of the prostate. Urology 1991, 27:260-262.

36. Kuwahara M, Matsushita K, Yoshinaga H, Aki M, Fujisaki N, Furihata M, Ohtsuki Y: Primary squamous cell carcinoma of the prostate: a case report. Hinyokika Kiyo 1993, 39:77-80.

37. Perez Garcia FJ, Veiga Gonzalez M, Rodriguez Martinez JJ, Rabade Rey CJ, Fernandez Gomez JM, Escaf S, Martin Benito JL: Squamous cell carcinoma of the prostate: presentation of a case and review of the literature. Actas Urol Esp 1997, 21:931-935.

38. Ulloa SA, Iturregui IR, Amezquita M, Ortiz VN: Squamous cell carcinoma of the prostate: a case report and review of the literature. Bol Assoc Med PR 1997, 89: 192-194.

39. Rahmanou F, Koo J, Marinbakh AY, Solliday MP, Grob BM, Chin NW: Squamous cell carcinoma at the prostatectomy site: squamous differentiation of recurrent prostate carcinoma. Urology 1999, 54:744.

40. Puyol Pallas M, Badia F, Gomez Parada J: Squamous cell carcinoma of the prostate. Actas Urol Esp 2001, 25:71-73.
4I. Nabi G, Ansari MS, Singh I, Sharma MC, Dogra PN: Primary squamous cell carcinoma of the prostate: a rare clinicopathological entity. Report of $\mathbf{2}$ cases and review of literature. Urol Int 200I, 66:216-219.

42. Goto $T$, Noguchi A, Hamamoto $Y$, Minoshima K, Taniguchi M, Takeuchi T, Sakai S, Iwata H, Sasaoka I: Primary squamous cell carcinoma of the prostate forming a rectourethral fistula: a case report. Hinyokika Kiyo 200I, 47:433-436.

43. Herrera Puerto J, Barragan Casas JM, Hovos Fitto C, Isusquiza Garro I, Pierna Manzano J: Squamous cell carcinoma of the prostate: a further case. Actas Urol Esp 2002, 26:366-368.

44. Mayayo Vicente MS, Fernandez Arjona M, Gascon Veguin JP, Jimenez Sanchez F, Puig Rullan AM, Cortes Aranguez I: Prostatic epidermoid carcinoma: report of a new case and review of the literature. Arch Esp Urol 2003, 56:939-943.

45. Kanthan R, Torkian B: Squamous cell carcinoma of the prostate. A report of 6 cases. Urol Int 2004, 72:28-3I.

46. Parwani AV, Kronz JD, Genega EM, Gaudin P, Chang S, Epstein Jl: Prostate carcinoma with squamous differentiation. Am J Surg Pathol 2004, 28:65 I-657.

47. John TT, Bashir J, Burrow CT, Machin DG: Squamous cell carcinoma of the prostate - A case report. Int Urol Nephrol 2005, 37:3II-3I3

48. Di Pietro C, Celia A, De Stefani S, Saredi G, Bianchi G: Squamous cell carcinoma of the prostate. Arch Ital Urol Androl 2006, 78:75-76.

49. Inaba M, Boku H, Tanaka S, Fujito A: Primary squamous cell carcinoma of the prostate: a case report. Hinyokika Kiko 2007, 53:39-4I.

Publish with Bio Med Central and every scientist can read your work free of charge

"BioMed Central will be the most significant development for disseminating the results of biomedical research in our lifetime. "

Sir Paul Nurse, Cancer Research UK

Your research papers will be:

- available free of charge to the entire biomedical community

- peer reviewed and published immediately upon acceptance

- cited in PubMed and archived on PubMed Central

- yours - you keep the copyright 